\title{
The Comprehensive Evaluation Model of Low Carbon Benefits of the Power Planning and Its Application
}

\author{
Xiaohui Zhang ${ }^{1, a}$, Xuewei Ren ${ }^{2, b}$ and Jiaqing Zhong ${ }^{3, c}$ \\ ${ }^{1,2,3}$ College of Electrical Engineering, Yanshan University, Qinhuangdao, Hebei Province, China \\ axhzhang@ysu.edu.cn, b1063498014@qq.com, cjqzhong@ysu.edu.cn
}

\begin{abstract}
Keywords: low-carbon economy, the power planning, low-carbon benefits, the comprehensive cost
\end{abstract} of low-carbon, carbon emission.

\begin{abstract}
Analyze the formation mechanism of low carbon benefits of the low carbon power, and combine the economic and low carbon characteristics of a low carbon power by using the low carbon economic factors, redefine low carbon benefits of the power planning and form a comprehensive evaluation model of low carbon benefits. And simulationly analyze the power planning for the least low carbon comprehensive cost as the objective function according to the design case of the typical low carbon power supply, quantitatively evaluate low carbon comprehensive benefits of the power planning. The result shows that the low carbon power planning has a lot of low carbon benefits compared with the traditional power supply planning.
\end{abstract}

\section{Introduction}

From the point of view, low carbon power planning can adapt to the development of low carbon requirements. However, the low carbon benefits of power planning has not a quantitative standard, set up low carbon benefits evaluation of power supply system, convenient for performance analysis of low carbon power supply for the promotion of low carbon power source planning and developing direction of master also has a great significance.

In recent years, the research of the low carbon power has widely spread, Comprehensive analysis of the literature [2] in a low carbon economy of electric power industry faces new situation and presents new characteristics, and set up the overall research framework of low-carbon electricity technologies; Literature [3] is analyzed for low carbon target model of the power planning. Literature[4] excavates low carbon benefits of the grid, the low carbon benefits evaluation model of the grid is set up, and puts forward the concept of low carbon electricity technology analysis. Literature [5] proposed a smart grid item to promote the development of low carbon ability, and dig deep and analyzed the coupling between each individual ability, put forward the comprehensive low carbon ability evaluation model and the final formation of the low carbon benefits comprehensive evaluation model of the smart grid. Literature[6-7] understand the concept of low carbon benefit of power grid from different angles $t$, and different analysis model is given.

Above all, low carbon benefits model of power planning and evaluate comprehensively low carbon benefits of the power planning are not given, this article analyzes the formation mechanism of low carbon benefits of the low carbon power, and combines the economic and low carbon characteristics of a low carbon power by using the low carbon economic factors, redefines low carbon benefits of the power planning and form a comprehensive evaluation model of low carbon benefits, and simulationly analyzes the power planning for the least low carbon comprehensive cost as the objective function according to the design case of the typical low carbon power supply, quantitatively evaluates low carbon comprehensive benefits of the power planning. The result shows that the low carbon power planning has a lot of low carbon benefits compared with the traditional power supply planning.

\section{The Low-carbon Comprehensive Benefit Analysis Model of Power Supply Planning}

Definition of Low-carbon Comprehensive Benefits of Power Planning. Low-carbon comprehensive benefits of power planning includes two aspects of content, one is the benefits of 
low-carbon cost, on the other hand is carbon emission reduction benefits.

First of all, define the benefits of low-carbon cost of the power planning: The impose of carbon taxes increases the cost of carbon, and carbon trading mechanism has brought the corresponding carbon earnings for the power planning. Carbon cost and carbon earnings can be integrated comprehensive carbon cost, with the numerical summing of the traditional power planning cost, namely get low-carbon comprehensive cost of low-carbon power planning. In the analysis of the benefits of low-carbon cost of the power planning, usually want to have a comparative object, under the same working conditions can be the traditional power planning. The difference value of the comparative object and the low-carbon comprehensive cost of low-carbon power planning is the benefits of low-carbon cost.

Carbon emission reduction benefits refers to the difference value between the total carbon emissions of the traditional power planning and the low-carbon power planning during the planning period.

The Model of Low-carbon Comprehensive Cost of Low-carbon Power Planning. Low-carbon comprehensive cost of low-carbon power planning includes the cost of investment, operation maintenance cost, power generation cost and the comprehensive carbon cost.

The cost of investment:

$$
C_{I}^{(t)}=\sum_{k} Y_{k}^{(t)} C_{I k}^{(t)}
$$

The cost of operation maintenance:

$$
C_{O}^{(t)}=\sum_{k} H_{k}^{(t)} C_{O k}^{(t)}
$$

The cost of power generation:

$$
C_{G}^{(t)}=\sum_{k} A_{k}^{(t)} C_{G k}^{(t)}
$$

The comprehensive carbon cost:

$$
C_{\mathrm{CO}_{2}}^{(t)}=E_{\mathrm{CO}_{2}} T_{\mathrm{C}}-E_{\mathrm{CDM}} P_{T}
$$

Where $Y_{\mathrm{k}}^{(t)}$ is expanded capacity of plant set $\mathrm{k}$ in year $\mathrm{t}$; $H_{k}^{(t)}$ is the total capacity of plant set k in year $\mathrm{t}$; $A_{k}^{(t)}$ is yearly generation capacity to plant $\mathrm{k}$ in year $\mathrm{t} ; \mathrm{c}_{I k}^{(\mathrm{t})} 、 C_{O k}^{(t)} 、 C_{G K}^{(\mathrm{t})}$ respectively denote the unit cost of investment, the unit cost of operation maintenance, the unit cost of power generation of plant set $\mathrm{k}$ in year $\mathrm{t} ; T_{C}$ and $P_{T}$ respectively denote carbon taxes and the price of carbon trading in year $\mathrm{t}$; $E_{\mathrm{CO}_{2}}$ is the total of carbon emissions in year $\mathrm{t}, E_{C D M}$ is the carbon trading volume in year $\mathrm{t}$.

$$
\begin{aligned}
& E_{\mathrm{CO}_{2}}=\sum_{k} e_{k}^{(t)} A_{k}^{(t)} \\
& E_{\mathrm{CDM}}=E_{G O V}^{(t)}-E_{\mathrm{CO}_{2}}
\end{aligned}
$$

Where $E_{G O V}{ }^{(t)}$ is the carbon emissions allowed of the planning in year $\mathrm{t}$; $e_{K}{ }^{(t)}$ is the carbon intensity of the unit generation capacity of plant set $\mathrm{k}$ in year $\mathrm{t}$.

In considering of the technical progress factor to carbon emissions intensity of each kind of generating set:

$$
e_{k}^{(t)}=e_{k}^{(t-1)}(1-\mu)(0<\mu<1)
$$

Where $\mu$ is the rate of technical progress .

The model of low-carbon comprehensive cost of low-carbon power planning:

$$
C_{S}=C_{I}^{(t)}+C_{O}^{(t)}+C_{G}^{(t)}+C_{\mathrm{CO}_{2}}^{(t)}
$$

The Low-carbon Comprehensive Benefit Analysis Model of Power Supply Planning

$$
\left.\begin{array}{l}
B_{S}=C_{S}^{\prime}-C_{S} \\
D_{S}=E_{T}^{\prime}-E_{T}
\end{array}\right\}
$$


Where $B_{S}$ and $D_{S}$ respectively denote the benefits of low-carbon cost and carbon emission reduction benefits; $C_{S}^{\prime}$ is the comprehensive cost of traditional power planning during the planning period; $E_{T}^{\prime}$ and $E_{T}$ respectively denote the carbon emissions of traditional power planning and low-carbon power planning during the planning period.

\section{Low-carbon Power Optimization Based on the Model of Low-carbon Comprehensive Cost}

Objective Function. The scheme minimizes the aggregate of the overall cost:

$$
\min C=\sum_{t=1}^{T} C_{R F} C_{S}
$$

Where $C_{R F}$ is capital recovery factor.

Constraint. 1 )Equation on Power Demand and Supply: Electricity that generated by plants should be equal to the anticipated power demand annually, which is

$$
\sum_{k \in N_{k}} A_{k}^{(t)}=Q^{t}
$$

2) Bounds on Yearly Power Generations of Plants.

$$
h_{k l}^{t} H_{k}^{(t)} \leq A_{k}^{(t)} \leq H_{k}^{(t)} h_{k u}^{t}
$$

Where $\mathrm{h}_{\mathrm{k}_{\mathrm{u}}}^{\mathrm{t}}$ and $\mathrm{h}_{\mathrm{k}_{\mathrm{l}}}^{\mathrm{t}}$ is the upper and lower bounds of yearly generating hour.

3) Limits on Cumulative Capacities: Cumulative capacities for every set of plants should be limited.

$$
H_{k}^{(t)} \leq \lim Q_{k}^{t}
$$

Where $\lim Q_{k}{ }^{t}$ is maxium value of cumulative capacities for every set of plants in year t.

4) Caps on Exploitable Capacity.

$$
\sum_{\mathrm{t}=1}^{T} Y_{k}^{(t)} \leq \operatorname{Lim}_{k}
$$

Where $\operatorname{Lim}_{\mathrm{k}}$ is caps of exploitable capacity for resource k during the planning period;

5) Constraints on carbon emissions:

$$
\begin{aligned}
& \sum_{k \in N_{K}} \mathrm{e}_{k}{ }^{(t)} A_{k}{ }^{(t)}+E_{S}^{t}-E_{B}^{t} \leq E_{G O V}^{t} \\
& \sum \mathrm{e}_{k}^{T} A_{k}^{T} \leq E^{T}
\end{aligned}
$$

The formula (15) denote constraints on carbon emission annually; The formula (16) denote constraints on carbon emissions at the end of the planning period; $E_{S}{ }^{t}$ and $E_{B}{ }^{t}$ respectively denote the selling and buying carbon quotas; $E^{T}$ is the carbon emissions at the end of the planning period.

\section{Analysis of Examples}

Basic Data. The optimization of power source structure on an area of our country in 2015-2024 is based on the low-carbon power planning model of this article. By the end of 2014, the province's biggest load is $84875 \mathrm{mw}$, assuming that the load increasing 10\% per year during the planning period. In 2014, the intensity of carbon emissions is $0.65 \mathrm{~kg} / \mathrm{kWh}$, policy for carbon emissions requires carbon emissions fall to $0.5 \mathrm{~kg} / \mathrm{kWh}$ by 2024 . Assuming the inflation rate is $3 \%$; The carbon tax price 
is RMB $100 ¥ / \mathrm{t}$; The CDM trading price is $70 ¥ / \mathrm{t}$. Specific datas are shown in Table 1 and Table 2.

Table.1 Relevant data of candidate power plans

\begin{tabular}{ccc}
\hline Power types & $\begin{array}{c}\text { Capacity of plant in } \\
2014 / \mathrm{GW}\end{array}$ & $\begin{array}{c}\text { Available capacity of plant during the } \\
\text { planning period/GW }\end{array}$ \\
\hline Thermal power & 55 & - \\
Natural gas & 2.94 & - \\
Hydropower & 9.17 & 20 \\
Wind power & 1 & 5 \\
Nuclear power & 0 & 8 \\
PV & 0 & \\
\hline
\end{tabular}

Table. 2 Parameters for different types of units

\begin{tabular}{cccccc}
\hline Power types & $\begin{array}{c}\text { The cost of } \\
\text { investment } \\
(¥ / \mathrm{kW})\end{array}$ & $\begin{array}{c}\text { The cost of } \\
\text { operation } \\
\text { maintenance } \\
(¥ / \mathrm{kW})\end{array}$ & $\begin{array}{c}\text { The cost of power } \\
\text { generation } \\
(¥ / \mathrm{kWh})\end{array}$ & $\begin{array}{c}\text { Carbon intensity } \\
(\mathrm{kg} / \mathrm{kWh})\end{array}$ & $\mu$ \\
\hline Thermal power & 4500 & 135 & 0.25 & 0.85 & 0.01 \\
Natural gas & 3000 & 60 & 0.32 & 0.36 & 0.02 \\
Hydropower & 8500 & 170 & 0 & 0 & - \\
Wind power & 10000 & 200 & 0 & 0 & - \\
Nuclear power & 12500 & 250 & 0 & 0 & - \\
PV & 24000 & 480 & 0 & 0 & - \\
\hline
\end{tabular}

Result. According to the basic data, we get all kinds of power capacity expansion plan during the planning period, as shown in Figure 1.

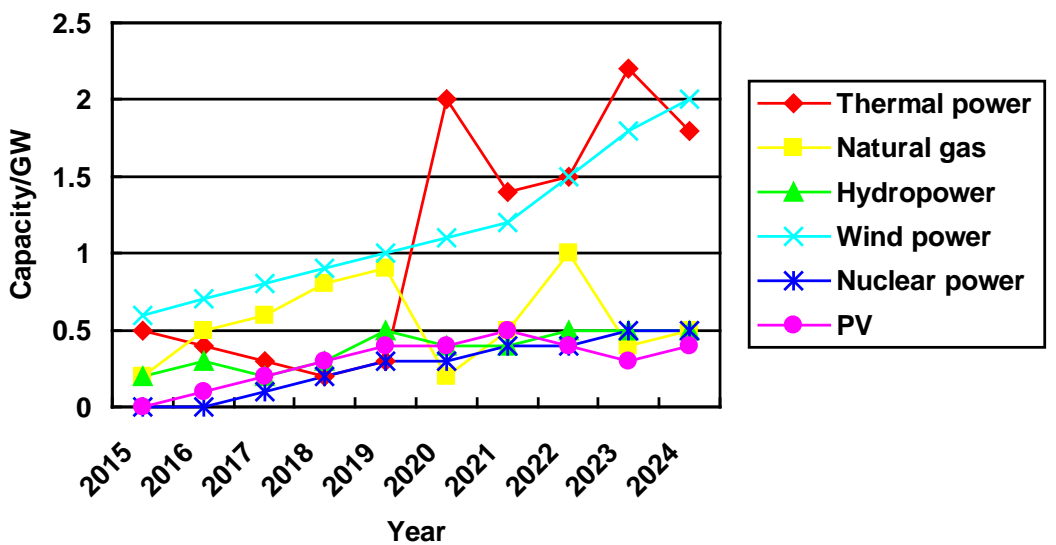

Figure.1 Capacity expansion plan

From Figure 1, on the premise of economic and environmental constraints, clean energy get to vigorously develop, in which, by in wind power technology is relatively mature, equipment investment and later operation maintenance cost is low, so the wind power becomes the development of the new energy. In carbon emissions constraints, especially at the end of the planning of carbon emissions constraints, the power structure will gradually adjust: By reducing the proportion of traditional fossil energy represented by thermal power; At the same time improve the proportion of new energy represented by wind.

The investment cost, operation maintenance cost, power cost, comprehensive carbon cost and carbon emissions of system during the planning period are shown in Table 3. 
Table.3 Costs and carbon emissions for the planning period

\begin{tabular}{|c|c|c|c|c|c|c|}
\hline Year & $\begin{array}{l}\text { The investment } \\
\text { cost } \\
\text { /100million } ¥\end{array}$ & $\begin{array}{l}\text { The operation } \\
\text { cost } \\
\text { /100million } ¥\end{array}$ & $\begin{array}{l}\text { The generation } \\
\text { cost } \\
\text { /100million } ¥\end{array}$ & $\begin{array}{l}\text { The comprehensive } \\
\text { carbon cost } \\
\text { /100million } ¥\end{array}$ & $\begin{array}{c}\text { Low-carbon } \\
\text { comprehensive } \\
\text { cost } \\
\text { /100million } ¥ \\
\end{array}$ & $\begin{array}{l}\text { Carbon } \\
\text { emissions } \\
\text { /100million t }\end{array}$ \\
\hline 2015 & 105.5 & 95.9 & 669.6 & 212.2 & 1082.3 & 2.21 \\
\hline 2016 & 152.5 & 99.1 & 681.3 & 220.4 & 1153.4 & 2.32 \\
\hline 2017 & 184 & 103 & 693.3 & 230.1 & 1210.4 & 2.45 \\
\hline 2018 & 221 & 106.2 & 707.1 & 245.5 & 1279.7 & 2.58 \\
\hline 2019 & 262.5 & 110 & 720.5 & 258.2 & 1350.2 & 2.71 \\
\hline 2020 & 302 & 115.2 & 725.8 & 278.4 & 1421.4 & 2.92 \\
\hline 2021 & 358 & 121.4 & 741.9 & 289.5 & 1510.8 & 3.03 \\
\hline 2022 & 405 & 126 & 758.2 & 300.6 & 1589.8 & 3.19 \\
\hline 2023 & 453 & 133.6 & 776.4 & 320.2 & 1683.2 & 3.37 \\
\hline 2024 & 497 & 143.7 & 793.8 & 338.8 & 1743.3 & 3.52 \\
\hline
\end{tabular}

The Comprehensive Evaluation of Low-carbon Benefits. In order to quantify the power planning of low carbon benefits, introduced traditional power planning, the traditional power supply planning does not consider the carbon tax and carbon trading, wind power and other clean energy technology, and carbon emissions constraints. Getting the low-carbon comprehensive cost and carbon emissions of traditional power planning in the planning period .Two planning models of key indicators are shown in Table 4 below.

Table.4 Comparison of results under two scenarios

\begin{tabular}{ccc}
\hline Model & Low-carbon comprehensive cost /billion $¥$ & Carbon emissions /billion t \\
\hline Low-carbon planning & 1402.46 & 2.83 \\
Traditional planning & 1412.59 & 3.71 \\
\hline
\end{tabular}

According to the Table 4 and the evaluation model of low-carbon benefits:

$B_{s}=D_{s}^{\prime}-D_{s}=1412.59-1402.46=10.13$ billion $¥$

$D_{s}=E_{T}^{\prime}-E_{T}=3.71-2.83=0.88$ billion $\mathrm{t}$

Getting low-carbon cost benefits is 10.13 billion $¥$, carbon emission reduction benefits is 0.88 billion t, low-carbon power planning has the huge low-carbon comprehensive benefit.

\section{Conclusions}

This article analyzes the formation mechanism of low carbon benefits of the low carbon power, and combines the economic and low carbon characteristics of a low carbon power by using the low carbon economic factors, redefines low carbon benefits of the power planning and form a comprehensive evaluation model of low carbon benefits, and simulatedly analyzes the power planning for the least low carbon comprehensive cost as the objective function according to the design case of the typical low carbon power supply, quantitatively evaluates low carbon comprehensive benefits of the power planning. The result shows that the low carbon power planning has a lot of low carbon benefits compared with the traditional power supply planning.

\section{Acknowledgements}

This work was financially supported by the Natural Science Foundation of Hebei Province (E2014203250),and the Young Teachers Independent Research Project Subject Foundation of Yanshan University (13LGA009),. 


\section{References}

[1] IPCC. Intergovernmental panel for climate change(IPCC) fourth assessment report. Cambridge, UK: Cambridge University Press, 2007.

[2] Energy Information Administration. World carbon dioxide emissions from the consumption and flaring of fossil fuels,2008. http://www. eia. doe.gov/iea/carbon.html.

[3] GRUBB M, JAMASB T, POLLITT M G. Delivering a low-carbon electricity system. Cambridge, UK: Cambridge,University Press, 2008.

[4] Yuan C,Li F,Kuri B. Optimal power generation mix towards an emission target[C].Proceedings of the IEEE Power and Energy Society General Meeting.Detroit,USA:IEEE,2011:1-7.

[5] Unsihuay-Vila C,Marangon-Lima J W,Zambroni De Souza A C,et al .Multistage expansion planning of generation and interconnections with sustainable energy developmentcriter:a multi-objective model[J].International Journal of Electrical Power \& Energy Systems, 2011, 33(2):258-270.

[6] Qinxin Chen, Chongqing Kang. Power generation expansion planning model towards low-carbon economy and its application in China [J].IEEE Trans on Power Systems, 2010, 25(3):1117-1125.

[7] Zhou Xun, James G, Liebman A, et al. Partial carbon permits allocation of potential emission trading scheme in Australian electricity market[J].IEEE Trans on Power Systems, 2010, 25(1):543-553. 